\title{
IoT based Water Management System
}

\author{
Prof. R.R.Karhe ${ }^{1}$, Ms.Vaishali Dilip Kachawa ${ }^{2}$ \\ ${ }^{1}$ HOD, Department of Electronics and Telecommunication Engineering, Shri.GulabraoDeokar College of Engineering, Jalgaon \\ [M.S.], India \\ rajeshkarhe@yahoo.com \\ ${ }^{2}$ PG Student, Department of Electronics and Telecommunication Engineering, Shri. GulabraoDeokarCollege of Engineering, \\ Jalgaon [M.S.], India \\ vaishalik1992@gmail.com
}

\begin{abstract}
The conventional technique of measuring the quality of water is to gather the samples manually and send it laboratory for analysis, but this technique is time overwhelming and not economical. Since it is not feasible to take the water sample to the laboratory after every hour for measuring its quality. The water quality measuring system can measure the essential qualities of water in real time. The system consists of multiple sensors to measure the standard of water, microcontroller and wifi modem to send the information to the watching center. It's a true time system which is able to endlessly measure the standard of water and can send the measured values to the watching center when each predefinedtime.

During the past decade, water needs have increased unpredictably in India. Increasing demand of water supply has become a major challenge for the world. Wasteful usage of water, climatic changes and Urbanization has further depleted the resource. Conservation and management of the resource must be given utmost importance. In this paper, we present an IoT design for water monitoring and control approach which supports internet based data collection on real time bases. This paper proposes a system that addresses new challenges in the water sector flow rate measuring and the need for a study of the supply of water in order to curb water wastage and encourage its conservation. We also measure the quality of water distributed to every household by deploying $\mathrm{pH}$ and conductivity sensors. The traditional water metering systems require periodic human intervention for maintenance making it inconvenient and often least effective. This system is designed to overcome for shortcoming of the existing models for a ubiquitous usage of wireless systems for smart quality monitoring and communicate datawirelessly.
\end{abstract}

Keywords:pH,IR etc.

$* * * * *$

\section{INTRODUCTION}

Water is an important resource for all the livings on the earth. Water crisis is regarded as the number one global risk. Nearly 750 million people around the world lack access to safe waterwhich approximates to 1 in 9 people. Apart from this, $82 \%$ of those who lack access to improved water live in rural areas, while just $18 \%$ live in urban areas

In that, some people are not getting sufficient amount of water because of unequal distribution. We can use this approach so that everyone gets the equal amount of water. It is also used to avoid the wastage of water during the distribution period. In the previous method, the employee will go to that place and open the valve for a particular duration, then again the employee will go to the same place and close the valve, it is waste of time. This system is fully automated. Here human work and time are saved. To ensure the safe supply of drinking water the quality should be monitored in real time for that purpose new approach IOT (Internet of Things) based water quality monitoring has been proposed. In this project, we will implement the design of IOT base water quality monitoring system that monitors the quality of water in real time. This system consists some sensors which measure the water quality parameter. The real-time monitoring of water resources information will benefit the water resources management department and the public. The primary concept of real-time IOT based water resources information system is to provide comprehensive and accurate information. The system is developed through defining some explicit water resource parameters then, Water level and flow parameter are defined for water measure \& management, followed by a sensor network for water resources information monitoring is constructed based on IOT.

The quality of water has an impact on the living beings. Water quality testing is an important part of environmental monitoring. Water quality refers to the chemical, physical, biological, and radiological characteristics of water. It is a measure of the condition of water relative to the requirements of one or more biotic species and or to any human need or purpose. In this project, the main parameters that define water quality are monitored and observed. To monitor the parameters different sensors like pH, IR, Temperature and Conductivity sensors are used. All the measured parameters are compared with the threshold value that defines the purity. Once the parameters are measured they are sent to authority in the form of alert messages

While automatically improving the water quality is not feasible at this point, efficient use oftechnology and economic practices can help improve water quality and awareness among people. 


\subsection{BLOCK DIAGRAM OF WATER MANAGEMENT SYSTEM}

\section{SYSTEM DESIGN AND DEVELOPMENT}

We have identified a suitable implementation model that consists of different sensor devices and other modules, their functionalities are shown in figure. In this implementation model we used ATMEGA 328 with Wi-Fi module. Inbuilt ADC and Wi-Fi module connects the embedded device to internet. Sensors are connected to Arduino UNO board for monitoring, ADC will convert the corresponding sensor reading to its digital value and from that value the corresponding environmental parameter will be evaluated. After sensing the data from different sensor devices, which are placed in particular area of interest. The sensed data will be automatically sent to the web server, when a proper connection is established with sever device.

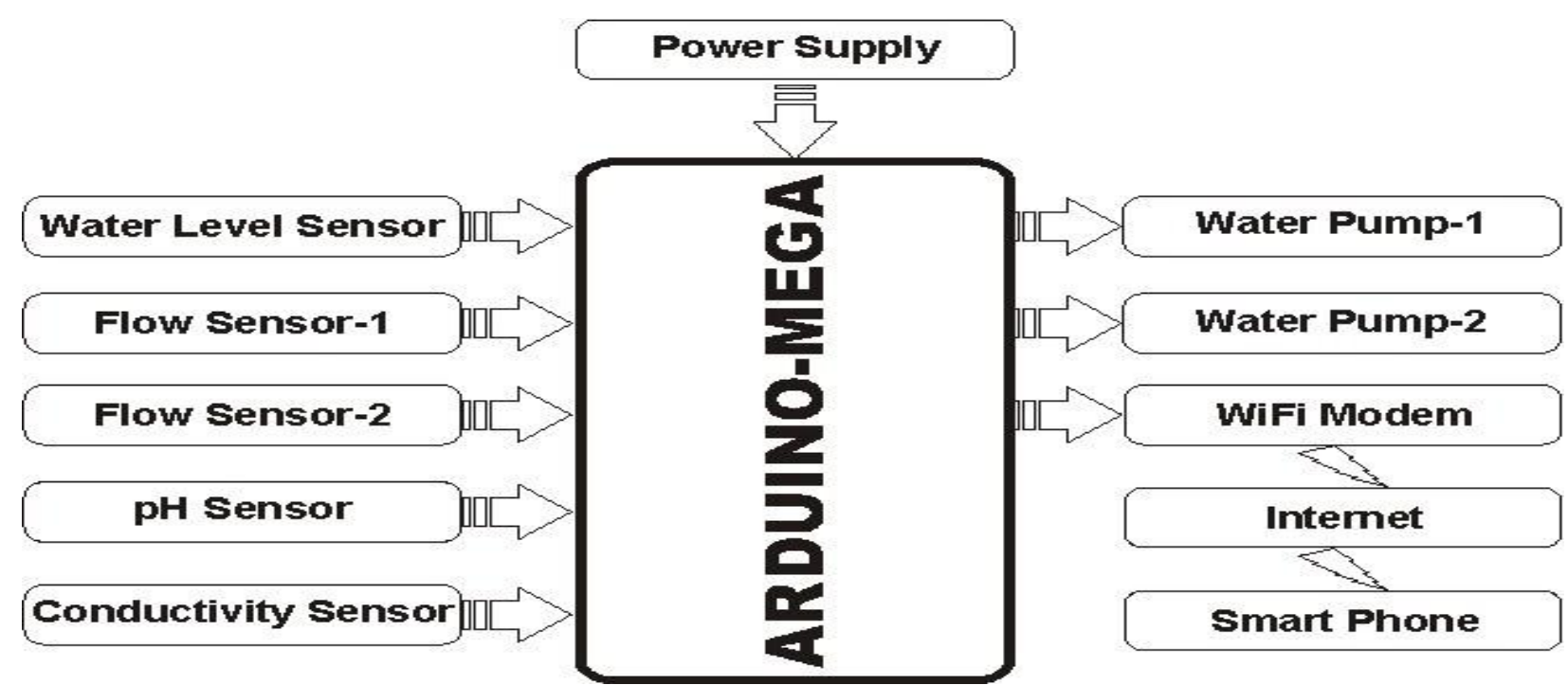

.Figure2.1 Block Diagram of Water Management System

\subsection{CIRCUIT DIAGRAM OF WATER MANAGEMENT SYSTEM}

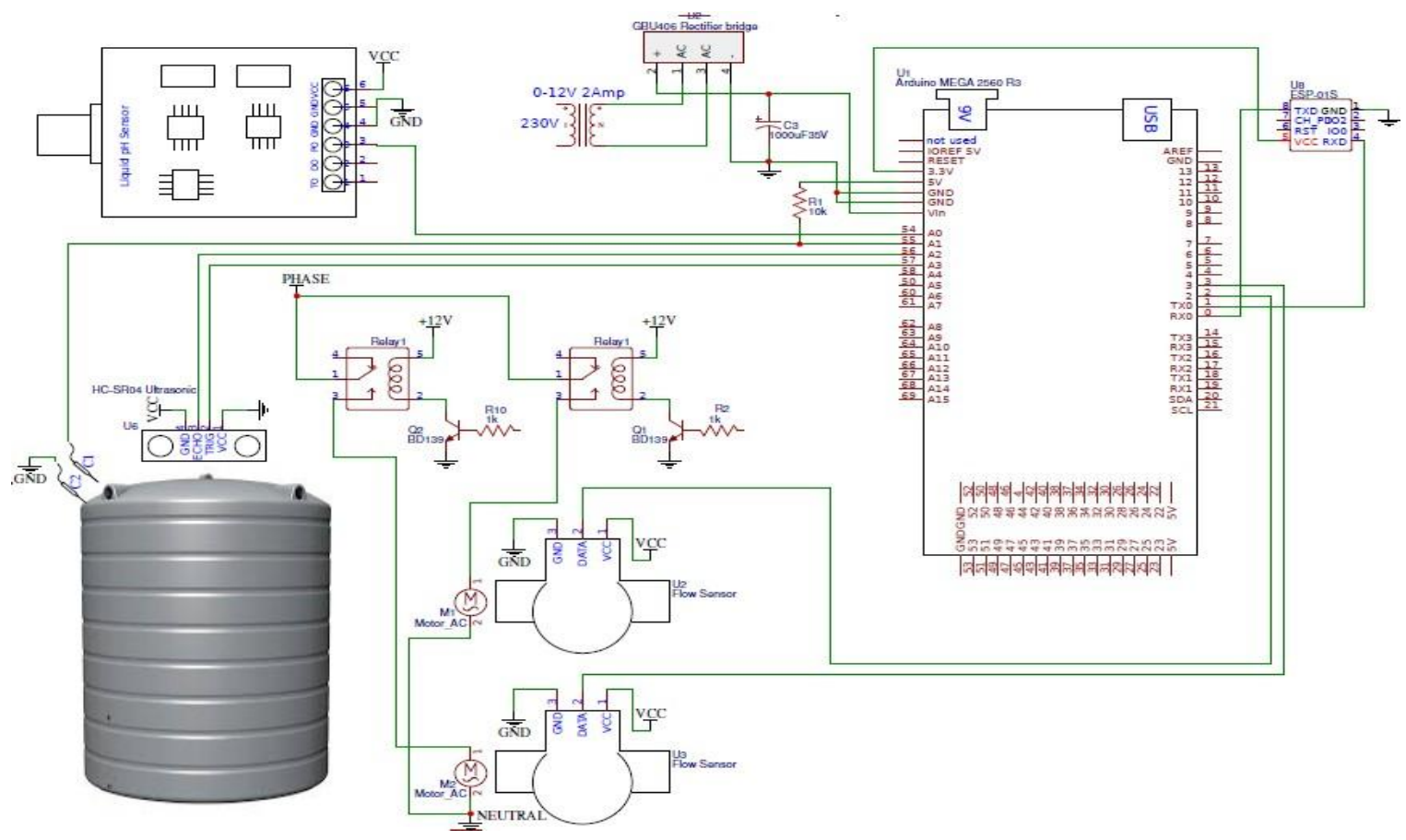

Figure 2.2 Circuit Diagram of Water Management System 


\subsection{EXECUTION TIMETEST}

\section{PERFORMANCE ANALYSIS}

When the supply is given to the system this signal is fed to the Arduino Microcontroller then Microcontroller process the signal and produced a desired output (Performs control action). This desired output is also transmitted by Wi-Fi transreceiver at controller side. The current status of Bin is displayed on IoT window. The required time for the complete process is few minutes.

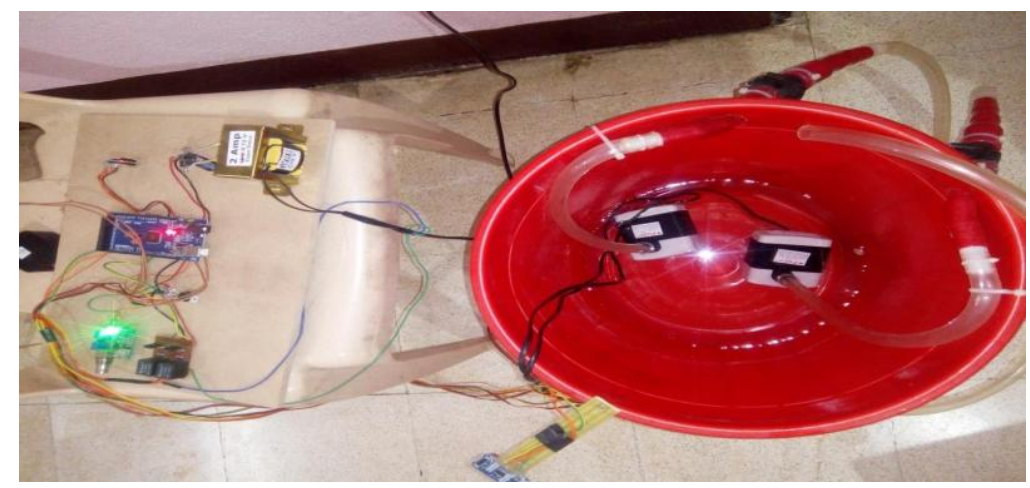

Figure 3.1 Hardware of IOT based water management system

\subsection{TESTING OF ULTRASONIC SENSOR}

Initially there is no water in tank so the reading of tank level is zero as soon as we start the water management system. The ultrasonic sensors detect the depth of water in the tank and gives signal to the microcontroller and we get different level reading Depending on water level on IoT platform window.

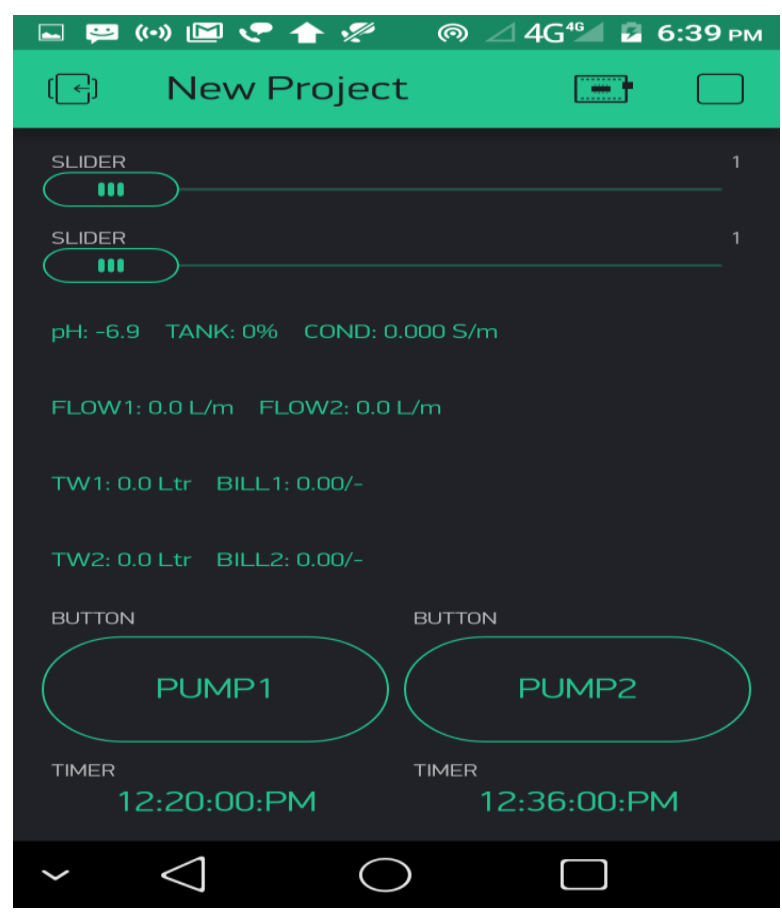

Figure 3.2 Output window before Execution of level sensor 


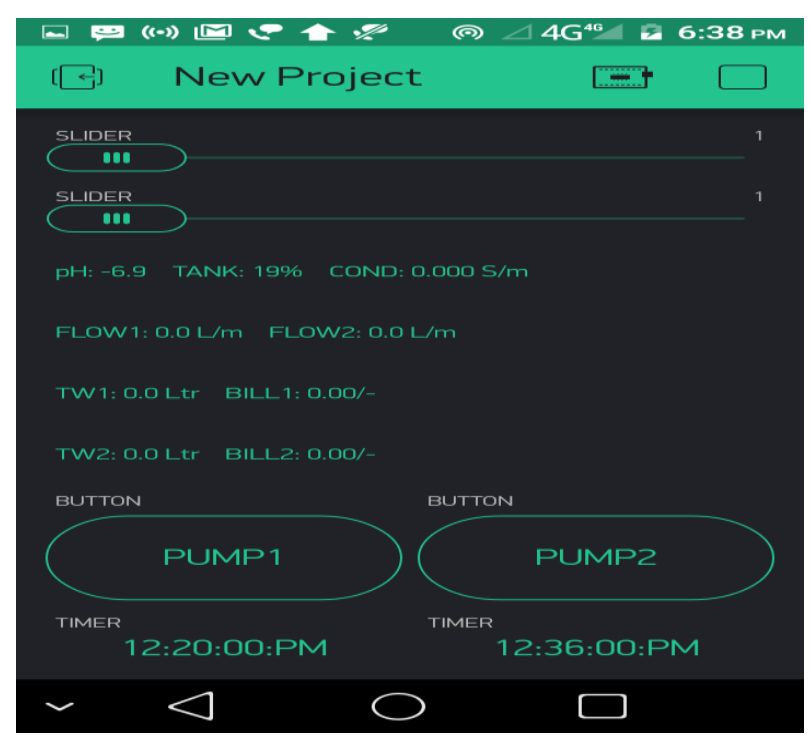

Figure 3.3 Output Window After Execution Of Level Sensor.

After addition of water in tank ultrasonic sensor senses the level of water. Here it shows that water tank is $19 \%$ fill. We can add more water in the tank. Ultrasonic sensor shows the level of tank fill by water.

\subsection{TESTING OF PHSENSOR}

$\mathrm{PH}$ sensor shows the ph value of sample water. Mineral water which has ph value equal to 7 is safe for drinking. In this project we have set the threshold value of ph 6.5 to 7.5 . Which means that below 6.5 ph water and above 7.5 ph water is not safe to drinking. Here we done testing for three conditions which are following-

\subsubsection{PH value below6.5}

Lemon juice have $\mathrm{PH}$ value 2. When the ph sensor is dip in to lemon juice it shows the value on the blynk application.

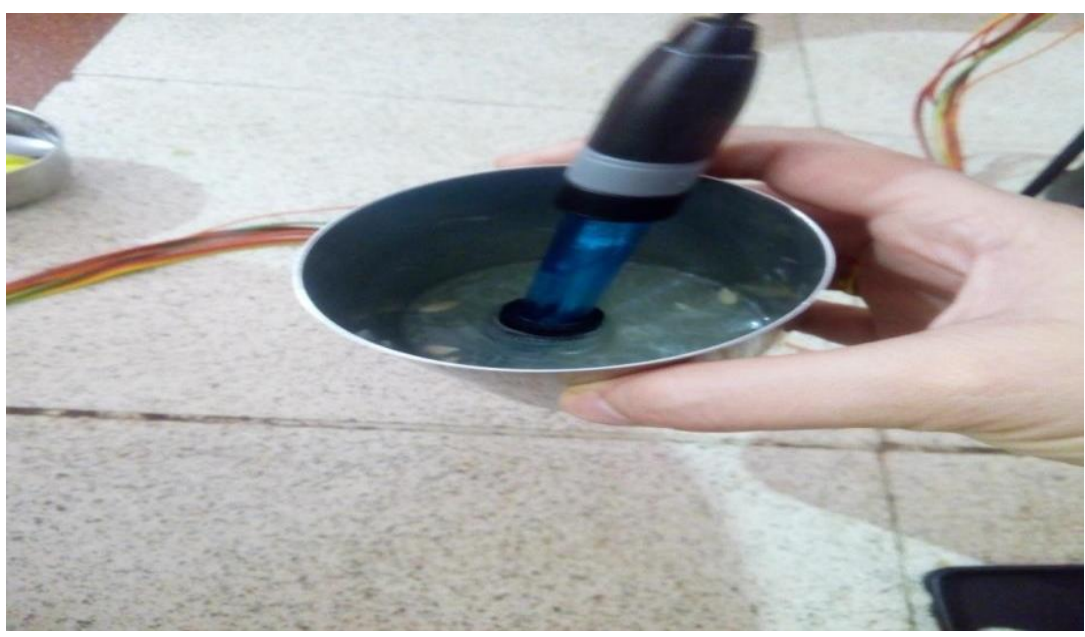

Figure 3.4 PH sensor dip into lemon juice 


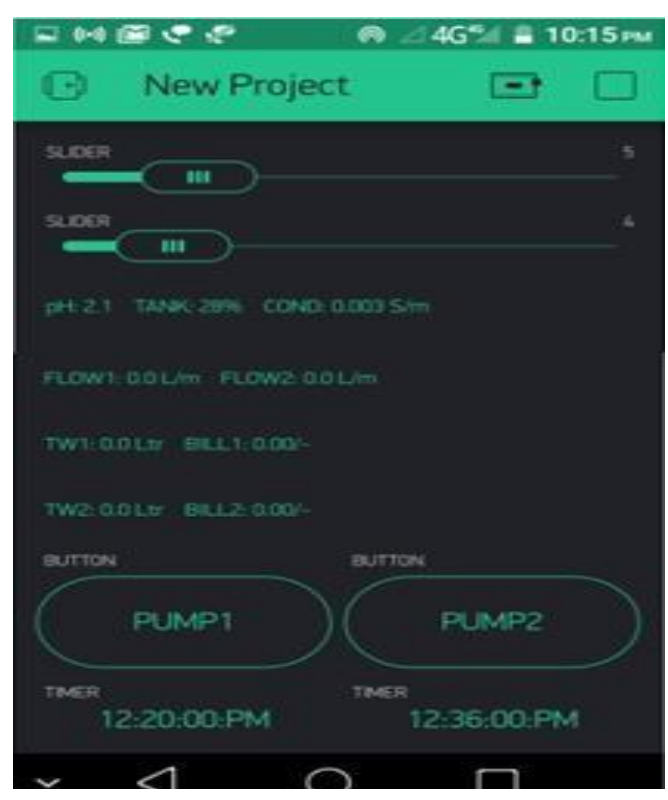

Figure 3.5 Blynk application shows the PH value

When the PH value is less than 6.5 then the flow sensor will not flow the water through the pump. This operation is done automatically. That means water will flow only when it has ideal range of PH value and it is safe to drink. It indicates alkalinity or acidity of a sample. PH value is measured in the scale of zero.

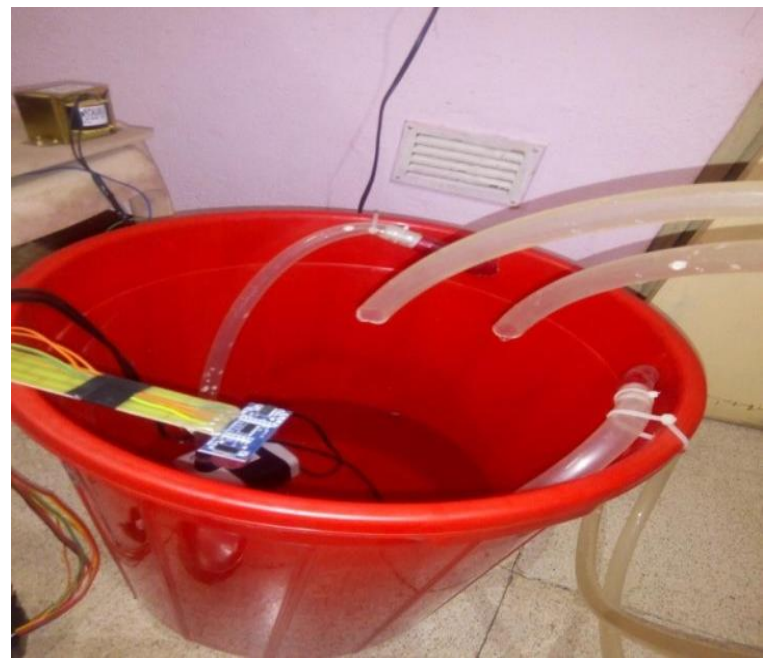

Figure 3.6 No water is flowing through the pipe

This diagram shows that no water flow through the pipe because water has low PH value. Therefore both the pipes are empty.

\subsubsection{PH value for6.5}

When PH sensor is dip into mineral water it shows the ph value 6.5 on the blynk. It also shows the flow rate of pump 1 in lit/min. It also calculate the total water provided to the user with electricity bill. PH is the most important parameter of water. It indicates alkalinity or acidity of a sample. $\mathrm{Ph}$ value is measured in the scale of zero to fourteen and temperature value is found between zero to eighty degreeCelsius. 


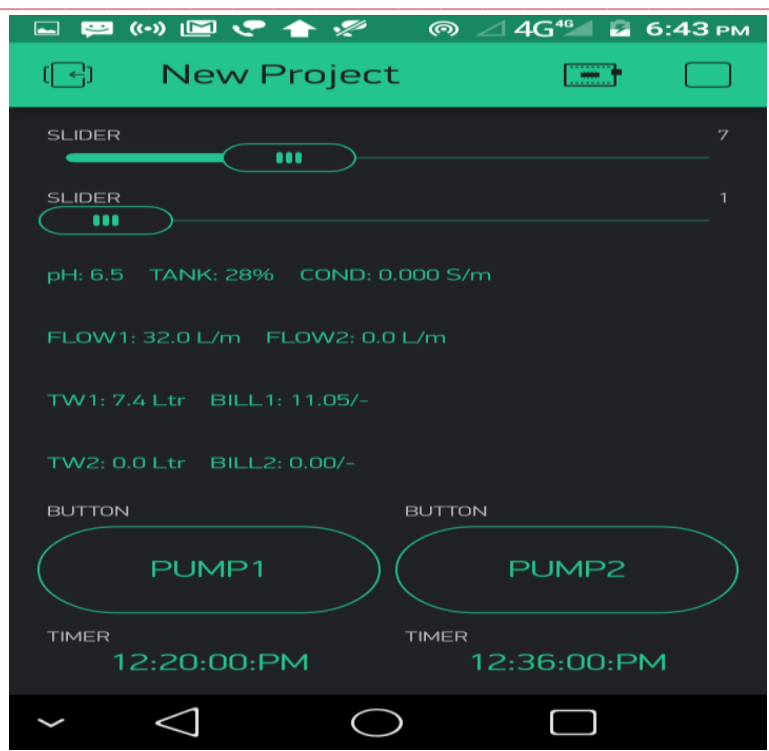

Fig 3.7 PH value of mineral water

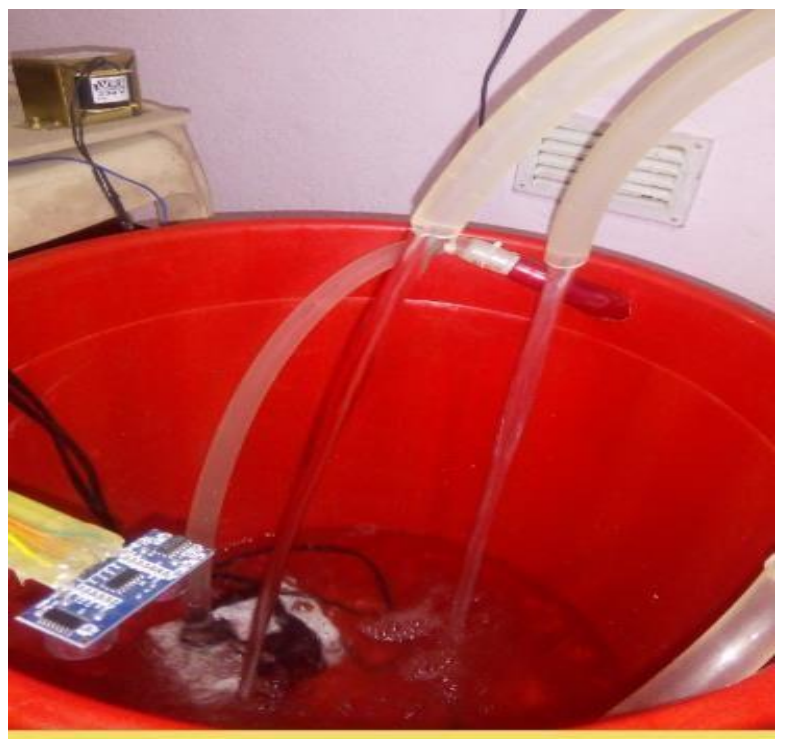

Fig. 3.8 Water flow through pipe

Here $\mathrm{PH}$ value show 6.5. This water is safe to drink, when water has safe $\mathrm{PH}$ range then only water will flow through pipe. When we press pump 1 button then through pump 1 water will flow. This procedure is same for pump 2 . We can press both the pump at a time. Both the pipe is flowingwater.

\subsubsection{PH VALUE ABOVE7.5}

When ph value exceed the normal range that indicates water having impurities in it and this water is not safe to drink. Here for testing purpose we have sample of baking soda. Baking soda has ph above 9. In this case water will not flow from the pipe. 


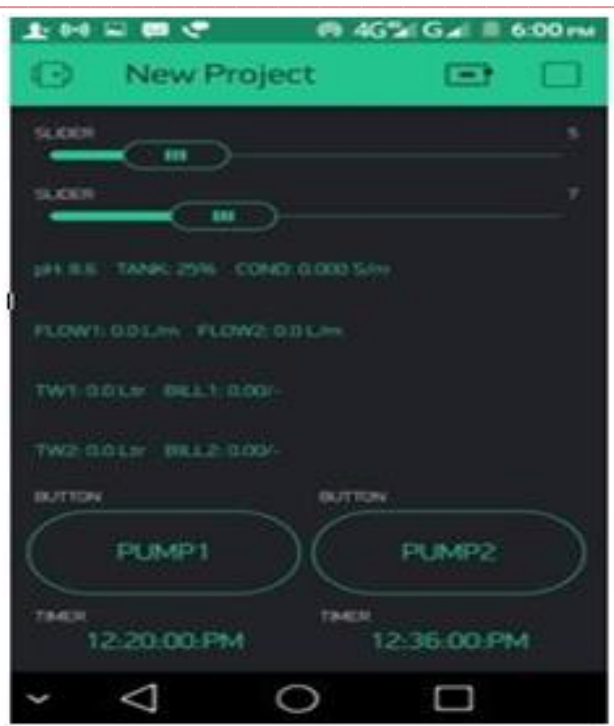

Figure 3.9 PH value above 7.5

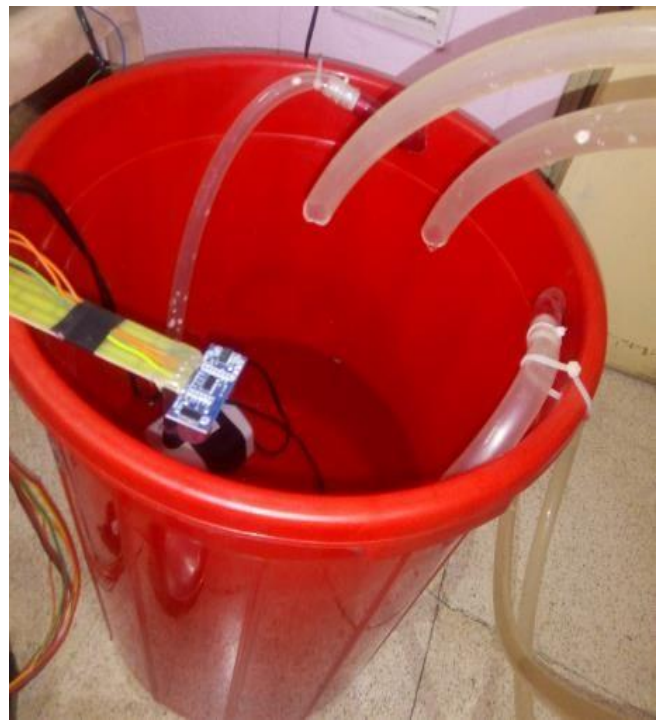

Figure 3.10 No water flow through pipel

Here PH value shows value 8.6. This water has no drinking quality. So here also no water will flow through pipe. Higher $\mathrm{PH}$ Value indicates that bad quality of water. If we press pump 1 button then no water will flow through the pipe. This is same for pump 2.

\subsection{TESTING FOR CONDUCTIVITYSENSOR}

When both the electrodes of conductivity sensor are dip into water, shows the value on the blynk application. It is measure in Siemens per meter. The measurement of product conductivity is a typical way to monitor and continuously trend the performance of water purification system. Conductivity is linked directly to the Total Dissolved Solids (T.D.S). 

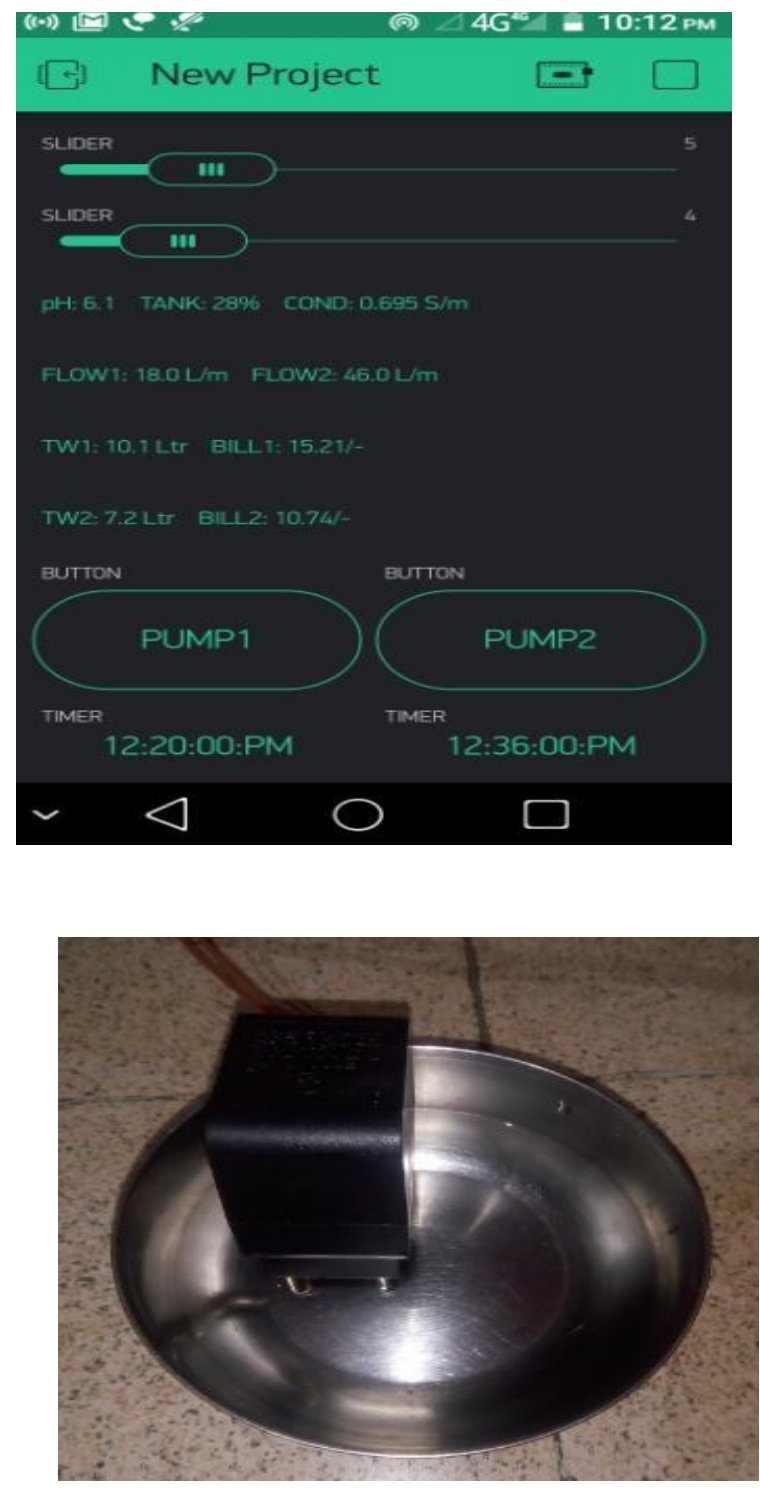

Figure 3.11 Measurement of Conductivity Sensor

Electrical conductivity is also an indicator of water quality. It measures free chlorine without sample pretreatment. It does not have messy and expensive reagents needed. Conductivity data can detect contaminants, determine the concentration of solutions and determine the purity of water. It is Compact in size. Conductivity sensor measures conductivity by AC voltage applied to nickel electrodes. These electrodes are placed in a water sample and reading is obtained.

\begin{tabular}{|l|l|l|l|l|l|l|l|l|l|l|}
\hline $\begin{array}{l}\text { Sr. } \\
\text { No. }\end{array}$ & Palue & Tank & ow 1 & pw 2 & W 1 & W 2 & mp 1 & mp 2 & ill 1 & ill 2 \\
\hline 1 & 2.1 & $19 \%$ & 00 & 00 & 0 lit & 0 lit & OFF & OFF & 0 Rs & 0 \\
& & & L/m & L/m & & & & & & \\
\hline 2 & 6.2 & $28 \%$ & 00 & 00 & 0 lit & 0 lit & OFF & OFF & 0 Rs & 0 \\
& & & L/m & L/m & & & & & & Rs \\
\hline
\end{tabular}




\begin{tabular}{|c|c|c|c|c|c|c|c|c|c|c|}
\hline 3 & 6.7 & $28 \%$ & $\begin{array}{l}32.0 \\
\mathrm{~L} / \mathrm{m}\end{array}$ & $\begin{array}{l}9.2 \\
\mathrm{~L} / \mathrm{m}\end{array}$ & $\begin{array}{l}7.4 \\
\text { Lit }\end{array}$ & $\begin{array}{l}0.1 \\
\text { lit }\end{array}$ & $\mathrm{ON}$ & $\mathrm{ON}$ & $\begin{array}{l}11.5 \\
\text { Rs }\end{array}$ & $\begin{array}{l}0.08 \\
\text { Rs }\end{array}$ \\
\hline 4 & 6.9 & $28 \%$ & $\begin{array}{l}32.0 \\
\mathrm{~L} / \mathrm{m}\end{array}$ & $\begin{array}{l}12.8 \\
\mathrm{~L} / \mathrm{m}\end{array}$ & $\begin{array}{l}7.4 \\
\text { Lit }\end{array}$ & $\begin{array}{l}5.1 \\
\text { lit }\end{array}$ & ON & ON & $\begin{array}{l}11.5 \\
\text { Rs }\end{array}$ & $\begin{array}{l}7.71 \\
\text { Rs }\end{array}$ \\
\hline 5 & 7.9 & $25 \%$ & $\begin{array}{l}00 \\
\mathrm{~L} / \mathrm{m}\end{array}$ & $\begin{array}{l}00 \\
\mathrm{~L} / \mathrm{m}\end{array}$ & $\begin{array}{l}0 \\
\text { Lit }\end{array}$ & 0 lit & OFF & OFF & $0 \mathrm{Rs}$ & $\begin{array}{l}0 \\
\text { Rs }\end{array}$ \\
\hline 6 & 8.6 & $25 \%$ & $\begin{array}{l}00 \\
\mathrm{~L} / \mathrm{m}\end{array}$ & $\begin{array}{l}00 \\
\mathrm{~L} / \mathrm{m}\end{array}$ & 0 lit & 0 lit & OFF & OFF & $0 \mathrm{Rs}$ & $\begin{array}{l}0 \\
\text { Rs }\end{array}$ \\
\hline
\end{tabular}

Table 3.1 Tabular Form of Result

Table 3.1 shows all the results in tabular form. We have experimented for different values of PH. If the ph value is above basic (means higher than 7) water is alkane. If it is below 7 the water is acidic. First two reading are done for below $6.5 \mathrm{PH}$ value. When $\mathrm{PH}$ value is less than 6.5, no water will flow through the pipe. So flow rate 1 and flow rate 2 are zero. Water will not flow through the pipe so total water will be zero. Pump have condition that, it will be ON only when PH has value in between 6.5 to 7.5 . Therefore, pump shows OFF condition.

Calculate the $\mathrm{PH}$ value for range 6.5 to 7.5 which safe water for drinking. When $\mathrm{PH}$ has its standard value then only pump will flow the water. When we press the pump1 button then water will flow through pipe having flow rate $32 \mathrm{~L} / \mathrm{m}$ for pump 1 . Both pumps in ON condition. Billing system is activated here, billing charges are applied are1.55 Rs. per litre.

Third condition mentioned here is having PH value above 7.5. When this condition satisfied no water will flow through the pipe. So flow rate $1 \&$ flow rate 2 both are zero. So total water is also zero and no bill generated for this waste water released from industries has usually $\mathrm{PH}$ in the range of 6.5 to 8.5 before water treatment. Our waste water sample also gave low PH value of 5.5. So it not safe to drink or use in any domestication purpose.

\subsection{ADVANTAGES}

\section{ADVANTAGES AND APPLICATIONS}

- Water Management

- Power Saver

- Money Saver

- Automatic

- Water Maximization

\subsection{APPLICATIONS}

- Water Conservation

- Smart Water Management

- Waste Water Management

- Water Quality Testing and Analysis

\section{CONCLUSIONS}

We successfully conducted our research and monitored water parameters such as conductivity, ph. Moreover we quantified relative value for water level and measure water consumption through flow sensor. Monitoring of conductivity, PH \& Temperature of Water makes use of water detection sensor with unique advantage and existing WI-FI network. The system can monitor water quality automatically, and it is low in cost and does not require people on duty. So the water quality testing is likely to be more economical, convenient and fast. The system has good flexibility. Only by replacing the corresponding sensors and changing the relevant software programs, this system can be used to monitor other water quality parameters. The operation is simple. 


\section{REFERENCES}

[1]. Nikhil Kedia, Water Quality Monitoring for Rural Areas- A Sensor Cloud Based Economical Project, in 1st International Conference on Next Generation Computing Technologies (NGCT-2015) Dehradun, India, 4-5 September 2015. 978-1-4673-6809- 4/15/\$31.00 (C)2015 IEEE

[2]. Jayti Bhatt, Jignesh Patoliya, Iot Based Water Quality Monitoring System, IRFIC, $21 \mathrm{feb}, 2016$.

[3]. Michal lom, ondrejpriby\&miroslavsvitek, Internet 4.0 as a part of smart cities, 978- 1-5090-1116-2/16/\$31.00 @ 2016 IEEE

[4]. Zhanwei Sun, Chi Harold Liu, ChatschikBisdikia_, Joel W. Branch and Bo Yang, 2012 9th Annual IEEE Communications Society Conference on Sensor, Mesh and Ad Hoc Communications and Networks (SECON), 978-1-4673-1905-8/12/\$31.00 @2012 IEEE

[5]. S. Geetha and S. Gouthami," Internet of things enabled real time water quality monitoring system", Springer open (2017) 2:1 DOI 10.1186/s40713-017-0005-y.

[6]. T. P. Lambrou, C. G. Panayiotou, and C. C. Anastasiou, A low-cost system for real time monitoring and assessment of potable water quality at consumer sites, in Proc. IEEE Sensors, Oct. 2012, pp. 1-4.

[7]. S. Zhuiykov, Solid-state sensors monitoring parameters of water quality for the next generation of wireless sensor networks,Sens. Actuators B, Chem., vol. 161, no. 1, pp. 1-20, 2012.

[8]. Aravinda S. Rao, Stephen Martial, JayavardhanaGubbi, MarimuthuPalani Swami,Design of low-cost autonomous water quality monitoring system, 2013 IEEE, pp. 14-19.

[9]. Niel Andre Cleote, Reza Malekian and Lakshmi Nair, Design of smart sensors for real- time water quality monitoring,vol 13, no. 9, September 2014 IEEE, pp. 1-16.

[10].PatawalaAmatulla. H, BansodeNavnath .P, Bhong Yogesh .P, "IOT Based Water Management System for Smart City," International Journal Of Advance Research Ideas And Innovation In Technology, ISSN: 2454-132X

[11].Prof. R. R. Karhe, Ms. Vaishali DilipKachawa,"IOT Based Water Management System," Internation Journal of Innovative Research In Technology (IJIRT) - Volume 6 Issue 2, July 2019, ISSN: 234960 